\title{
CONDIÇÕES DE LEITURA, RECEPÇÃO E EXEGESE DA OBRA BAKHTINIANA NO BRASIL*
}

\author{
Conditions of Reading, Condiciones de lectura, \\ Reception, and Exegesis recepción y exegesis \\ of the Bakhtinian Work in Brazil de la obra de Bajtín en Brasil
}

\author{
Nathan Bastos de Souza ${ }^{\star *}$ \\ Universidade Federal do Pampa (Unipampa), \\ Campus Bagé, RS, Brasil \\ Gabriella Cristina Vaz Camargo ${ }^{*+*}$ \\ Universidade Estadual Paulista (UNESP), \\ Faculdade de Ciências e Letras, Araraquara, SP, Brasil \\ Grenissa Bonvino Stafuzza ${ }^{* * * *}$ \\ Universidade Federal de Catalão (UFCAT), \\ Instituto de Estudos da Linguagem, Catalão, GO, Brasil
}

\begin{abstract}
Resumo: Este estudo apresenta elementos sobre as condições de leitura, recepção e exegese da obra bakhtiniana no Brasil. Para isso, levanta alguns aspectos biográficos de Bakhtin, Volóchinov e Medviédev, bem como um breve panorama histórico da recepção de seus textos na França, especialmente no final dos anos 60, com J. Kristeva. Ainda analisa quatro paratextos das obras de autores do Círculo de Bakhtin, com os quais debate as condições de leitura a partir de questões de tradução e recepção. Ao final, com base nas contribuições de Beth Brait, apresenta uma leitura da obra bakhtiniana com foco na Análise Dialógica do Discurso.
\end{abstract}

Palavras-chave: Obra bakhtiniana. Tradução. Recepção.

\begin{abstract}
This study presents elements about the conditions of reading, reception, and exegesis of Bakhtinian work in Brazil. For this purpose, it raises some biographical aspects of Bakhtin, Volochinov, and Medvedev, as well as a brief historical overview in respect of the reception of their texts in France, especially in the late ' 60 s with Julia Kristeva. In addition, it analyzes four paratexts of works by some authors from the Bakhtin Circle with which we discussed the conditions of reading by investigating translation and reception matters. At the end, based on Beth Brait's contributions, there is a reading of Bakhtinian work with a focus on the Dialogical Discourse Analysis (DDA).
\end{abstract}

Keywords: Bakhtinian work. Translation. Reception.

\footnotetext{
* O presente trabalho foi realizado com apoio da Coordenação de Aperfeiçoamento de Pessoal de Nível Superior - Brasil (CAPES) - Código de Financiamento 001.

** Doutor em Linguística pela Universidade Federal de São Carlos (UFSCar). ORCID: http://orcid.org/0000-0003-1560-2867. E-mail: nathanbastos600@gmail.com

**** Doutoranda em Linguística e Língua Portuguesa, Universidade Estadual Paulista - Campus Araraquara (UNESP/FCLAr). Bolsista CAPES. ORCID: https://orcid.org/0000-0002-2499-3460. E-mail: gabriella.v.camargo@unesp.br.

**** Doutora em Linguística e Língua Portuguesa. Docente do Programa de Pós-graduação em Estudos da Linguagem. ORCID: http://orcid.org/0000-0002-9077-0652. E-mail: grenissa@ gmail.com.
} 
Resumen: Este estudio presenta elementos sobre las condiciones de lectura, recepción y exegesis de la obra de Bajtín en Brasil. Para ello, recolecta algunos aspectos biográficos de Bajtín, Volóchinov y Médviédev, así como un conciso panorama histórico de la recepción de sus textos en Francia, especialmente a finales de los años 60, con J. Kristeva. Además, analiza cuatro paratextos de las obras de autores del Círculo de Bajtín, con las cuales discute las condiciones de lectura a partir de cuestiones de traducción y recepción. Al final, con base en contribuciones de Beth Brait, presenta una lectura de la obra de Bajtín con enfoque en el Análisis Dialógico del Discurso.

Palabras clave: Obra de Bajtín. Traducción. Recepción.

1 PRIMEIRAS PALAVRAS

Os estudos do discurso, no Brasil, servem de subsídio teórico e metodológico para inúmeras pesquisas, em diferentes níveis, desde iniciações científicas até teses de doutorado e relatórios de estágios pós-doutorais. Têm recebido atenção de diversos pesquisadores e grupos de pesquisa, nos quais se têm produzido as condições necessárias para o desenvolvimento de um trabalho analítico ao mesmo tempo à luz dos estudos de autores estrangeiros e desenvolvendo contribuições decisivas "à moda brasileira". Neste sentido, por exemplo, temos a Teoria do silêncio, desenvolvida por Eni Orlandi à luz de M. Pêcheux, a Semiótica da canção, desenvolvida por Luiz Tatit com base na semiótica greimasiana, e a Semântica do acontecimento, de Eduardo Guimarães, pautando-se em Ducrot e Benveniste.

A partir de algumas contribuições, nessa mesma linha de raciocínio, como Possenti e Baronas (2008), Paula e Stafuzza (2010) e Baronas (2015) ${ }^{1}$, trabalhamos com a hipótese de que as teorias do discurso se desenvolvem no Brasil à luz das teorias estrangeiras, mas aperfeiçoam seu arsenal teórico-metodológico para a análise de outros conjuntos de dados. Dessa maneira, temos uma análise do discurso à brasileira, no sentido de que as teorias discursivas se desenvolvem no Brasil porque encontram solo fértil e ampliam-se de acordo com a exigência dos diversos corpora analisados. A tendência em que nos inscrevemos, portanto, é de que há uma teorização sobre o discurso que se desenvolve com base nos estudos de outros autores, mas que já possui uma identidade brasileira.

Diante disso, voltamos nosso olhar para as leituras e discussões brasileiras atribuídas às obras que advém do Círculo de Bakhtin. Nessa mesma esteira de pensamentos, consideramos que os estudos bakhtinianos realizados hoje, no Brasil, também constroem seus próprios caminhos teórico-metodológicos. Assim, o objetivo deste artigo é discutir elementos que confirmam as condições de leitura, recepção e exegese da obra bakhtiniana no Brasil. Dessa maneira, este artigo está dividido em três

\footnotetext{
${ }^{1}$ Nessas obras, os autores e os organizadores partem de uma discussão sobre as ciências da linguagem desenvolvidas no Brasil que possuem influências advindas de outras teorias estrangeiras, como teorias francesas e/ou russas. Na obra de Baronas e Possenti (2008), por exemplo, o desenvolvimento das contribuições de Dominique Maingueneau para a AD no Brasil. Paula e Stafuzza (2010) trazem reflexões sobre o percurso histórico da análise do discurso francesa lida e debatida no Brasil e a constituição de uma análise do discurso brasileira, e em Baronas (2015) nos é apresentado um grande quadro de diversas vertentes de estudos discursivos à brasileira em uma obra que reúne estudiosos de semiótica da canção, da semântica enunciativa, da análise dialógica do discurso, da teoria do silêncio, dos estudos discursivos foucaultianos.
} 
partes que se complementam: na primeira são apresentados aspectos biográficos de Bakhtin, Volóchinov e Medviédev, em que é retomado um breve percurso histórico da escrita de seus textos e uma apresentação sobre como se deu a chegada, na França, das obras do Círculo de Bakhtin por meio da pesquisadora J. Kristeva, no final dos anos 1960; na segunda são analisados quatro paratextos das obras de autores do Círculo, com os quais discutimos as condições de leitura a partir de questões de tradução e de recepção; por fim, a terceira está reservada à apresentação de uma leitura da obra bakhtiniana à moda brasileira, com base nas contribuições de Beth Brait.

\section{A PRODUÇÃO DOS TEXTOS-FONTE E SUA CHEGADA À FRANÇA COM KRISTEVA}

A obra de Mikhail Bakhtin (1895-1975) tem chamado atenção internacional desde sua "redescoberta", nos anos 1960, na Rússia, por um grupo de estudantes. Sujeito do século XIX, Bakhtin foi contemporâneo da efervescência intelectual e da miséria pela qual a, então, União Soviética passou nos primeiros anos do século XX, sacudida pela Primeira Guerra Mundial (1914-1918) e pela Revolução Russa (1917), época em que começou seus estudos universitários. Nessa época participava com um grupo de amigos de reuniões periódicas, nas quais liam filosofia e faziam discussões.

Nos anos de 1920, algumas obras bastante importantes para o futuro da reflexão na área relacionada à linguagem foram produzidas e publicadas por Bakhtin e por pelo menos dois outros autores desse grupo, que viria a ser chamado depois de "Círculo de Bakhtin", Valentin Volóchinov² (1895-1936) e Pável Medviédev (1891-1938). Na recepção posterior das obras desses autores e nas traduções houve um movimento de neutralização da autoria de Volóchinov e Medviédev em favor de Bakhtin, uma vez que se acreditava que ele haveria escrito todos os textos e os amigos teriam emprestado seus nomes em razão da perseguição política de que era alvo no período. Essa questão gerou e ainda gera polêmica, e as traduções mais recentes (em diversos países) têm sido fiéis às publicações originais e "restituído" a autoria àqueles que figuravam nas capas das primeiras edições russas ${ }^{3}$.

De acordo com Grillo (2019, p. 23), em 13 de setembro de 1919 Bakhtin publicou seu primeiro texto, Arte e responsabilidade, no primeiro e único número de um

\footnotetext{
${ }^{2}$ A grafia do nome de Volóchinov varia de acordo com as edições das obras. No Brasil, há a grafia "Voloshinov", que advém de uma tradução do inglês, e "Volochínov" de uma tradução do francês com consulta à tradução do inglês. Neste trabalho, escolhemos utilizar "Volóchinov", consoante a tabela de transliteração russo-português formulada por pesquisadores da Universidade de São Paulo (USP) e utilizada na primeira tradução direta do russo de Marxismo e filosofia da linguagem (VOLÓCHINOV, 2017).

3 As traduções brasileiras, realizadas diretamente do russo, de Marxismo e filosofia da linguagem (VOLÓCHINOV, 2017) e O método formal nos estudos literários (MEDVIÉDEV, 2012), para citar duas das mais importantes obras em disputa, realizam essa "restituição", seguindo a tendência atual das traduções mais recentes dessas obras e de outras do chamado Círculo. Para os dois casos, há extensos ensaios introdutórios ou prefácios discutindo a temática. Nesse sentido, remetemos o leitor a essas contribuições que permitem entender a problemática de uma maneira mais ampla (ver GRILLO, 2012; 2017).
} 
almanaque da cidade em que vivia, em Niével, intitulado "Dia da Arte". Entre 1918 e 1924, trabalhou no texto Para uma filosofia do ato responsável, que se trata de um texto inacabado e que teve diversas folhas perdidas. Entre 1923 e 1924, trabalhou no texto $O$ autor e a personagem na atividade estética, que foi publicado em duas partes, primeiro em 1977 e depois em 1978; posteriormente, constituiu a coletânea Estética da criação verbal, de 1979.

Em 1929, Bakhtin publicou na Rússia seu primeiro livro, Problemas da obra de Dostoiévski; nessa época já se encontrava preso e um ano mais tarde sua pena seria transformada em exílio, no Cazaquistão. A acusação contra Bakhtin foi de participar de reuniões secretas que não correspondiam à estrutura política oficial da época e de fazer propaganda antissoviética (GRILLO, 2019, p. 29). Alguns anos mais tarde, em 1960, houve a chamada "redescoberta" de Bakhtin, por alguns estudantes, em uma biblioteca universitária. Bocharov, Gachev e Kojinov encontraram seu livro sobre Dostoiévski, de 1929, e entraram em contato com o autor, que naquele momento encontrava-se na função de professor de literatura universal no Instituto Pedagógico de Mordóvia, em Saransk, em pleno esquecimento intelectual de suas obras. Esses três estudantes começaram, então, a discutir a reedição desse livro, que em 1963 seria publicada em versão reformulada e aumentada com o título Problemas da poética de Dostoiévski ${ }^{4}$.

Ponzio (2012), em sua cronologia sobre o Círculo, informa que Volóchinov e Medviédev publicaram em 1925, respectivamente, um texto sobre o Freudismo e um texto sobre o "salierismo científico". No período entre 1926 e 1929, tanto Volóchinov quanto Medviédev, publicaram vários textos em revistas. O trio (Bakhtin, Volóchinov e Medviédev) publicou, nesse período, os seguintes livros: Freudismo, O método formal nos estudos literários, Marxismo e filosofia da linguagem e Problemas da obra de Dostoiévski. Somente o último, conforme comentamos anteriormente, foi publicado sob a assinatura de Bakhtin; a autoria dos outros textos, a posteriori, seria colocada em xeque - também de alguns ensaios de Volóchinov. A tuberculose de Volóchinov se agravou, o levando à morte em 1936; Medviédev publicou alguns textos, ainda nos anos 1930, até ser preso e condenado à morte em 1938.

Conforme os estudos de Grillo (2019, p. 32-34), Bakhtin, em 1941, apresentou o texto de sua tese de doutorado sobre cultura popular e François Rabelais, no Instituto da literatura mundial de Gorki, em Moscou, mas devido à Segunda Guerra Mundial, só conseguiu defendê-la em 1946. Após dividir inteiramente a sociedade acadêmica de Moscou, a defendeu novamente em 1949, em que teve negado seu título de doutor. Somente em 1952 recebeu o título de doutor, e em 1965 teve sua tese publicada, ainda com o auxílio dos estudantes universitários. Dessa forma, em 1963 e 1965, respectivamente, as obras Problemas da poética de Dostoiévski e A cultura popular na Idade Média e no Renascimento: o contexto de François Rabelais foram publicadas em russo.

Segundo as pesquisas de Ponzio (2012), Bakhtin seguiu publicando em revistas até sua morte, em 1975. Nesse mesmo ano, foi publicada, postumamente, a obra Questões de literatura e estética, e, conforme afirmamos, em 1979 foi publicada a primeira edição de

${ }^{4}$ Ver "Sobre o autor" em Bakhtin (2013, p. 117-118). 
Estética da criação verbal. Nos anos 1990 foram publicadas, na Rússia, as Obras completas, que figuram a maior parte dos textos encontrados em forma de manuscritos inacabados nos arquivos bakhtinianos.

Em 1967, uma resenha foi publicada por Julia Kristeva na revista Critique a respeito dos livros Problemas da poética de Dostoiévski e A cultura popular na Idade Média e no Renascimento: o contexto de François Rabelais. Kristeva, que cursava seu doutorado na França, havia lido Bakhtin em russo quando morava ainda na Bulgária; até então, Bakhtin era desconhecido por Roland Barthes e Gérard Genette, então professores de Kristeva. A autora preparou uma exposição sobre essas duas obras para um curso de Barthes e depois a publicou como resenha. No entanto, essa que seria a entrada de Bakhtin no universo ocidental foi mediada por uma "leitura singular" das obras, para a qual a própria autora veio a reconhecer mais tarde que fizera "adaptações”. Segundo Kristeva (1998, p. 19-20) em entrevista concedida a Clive Thonson, era necessário acomodar conceitos para que o leitor francês compreendesse a teoria, caso contrário, afirma a autora, Bakhtin poderia passar apenas como "fruto do folclore russo", do qual não conseguiria escapar e tampouco suscitar o interesse acadêmico atual.

A proposta de Kristeva foi aproximar conceitos bakhtinianos centrais, como diálogo e polifonia, de outros conceitos mais conhecidos pelos franceses versados em linguística e semiótica; daí surge o conceito de intertextualidade, inexistente em Bakhtin. Segundo dois tradutores da obra bakhtiniana, Bezerra (2015a) e Bubnova (2016), essa "adaptação" produziu uma deformação da teoria de base, isto é, induziu a erro de leitura. Para citar apenas dois exemplos desse amplo quadro de crítica à leitura de Kristeva formulado por esses autores, Bubnova (2016, p. 85) afirma que a noção de carnavalização na leitura feita por Kristeva, em 1967, trazia algumas generalizações como de que os romances polifônicos herdariam a estrutura carnavalesca menipeana ou conclusões doutrinárias como que os sujeitos seriam ocultos pelo discurso que os constituem. Nessa mesma esteira, Bezerra (2015a, p. XVII), também em torno da questão do sujeito nessa resenha de Kristeva em 1967, afirma que sua concepção de sujeito da escritura "que começa a se esfumar" estaria em "flagrante contradição com o pensamento de Bakhtin, que sempre enfatiza o papel do sujeito, quer como autor em todas as instâncias dos processos de criação, quer como leitor" (BEZERRA, 2015a, p. XVII). Esse erro de leitura, portanto, carregaria os traços específicos dos anos 1960 na França com a ascensão do pósestruturalismo e suas teses a respeito da morte do sujeito.

Diante dessas considerações sobre a biografia de Bakhtin, Volóchinov e Medviédev, o contexto histórico de produção dos textos e de sua chegada à França, nos dedicaremos a discutir as condições de leitura, sobretudo aquelas relativas à tradução e à recepção da obra de Bakhtin e do Círculo na seção seguinte.

\section{AS CONDIÇÕES DE LEITURA: QUESTÕES DE TRADUÇÃO E RECEPÇÃO}

Nesta seção apresentaremos as condições de leitura da obra bakhtiniana, no Brasil, através de uma chave de leitura que leve em conta as questões de tradução e recepção. 
Para tanto, trabalharemos com um conjunto de paratextos ${ }^{5}$ da obra em questão, quais sejam: a reflexão de Sériot (2015) sobre a obra Marxismo e filosofia da linguagem, texto publicado no Brasil como livro, mas preparado pelo autor como introdução à edição francesa da obra ${ }^{6}$; a introdução assinada por Geraldi (2013) ao conjunto de ensaios que reuniu e traduziu; dois glossários, o primeiro deles assinado por Bezerra (2015b) à obra de Bakhtin (2015b) Teoria do romance I: a estilística; e o segundo assinado por Grillo e Américo (2017) para Marxismo de filosofia da linguagem (VOLÓCHINOV, 2017).

Nessa esteira, uma questão importante é que ler Bakhtin e o Círculo, hoje, é estar sujeito a algumas condições de leitura que o conjunto de sua obra sofreu até chegar à ciência da linguagem brasileira. Desses determinantes exteriores à obra, destacaremos dois que são essenciais para entender o desenvolvimento e as contribuições à teoria dialógica: a tradução dos textos e a exegese da obra.

Sobre o desencontro entre as datas de produção e de publicação dos originais em russo $^{7}$, o esforço de leitura e tradução desses mesmos textos, anos mais tarde, em diferentes geografias, foi marcado por essas contingências espaçotemporais e também por injunções político-ideológicas. Acerca disso, Sériot (2015) afirma:

\begin{abstract}
A história aleatória e tortuosa das traduções fez com que somente Bakhtin fosse catapultado para o centro do palco do "Ocidente", cortado de suas fontes, arrancado de seu contexto, privado de qualquer ponto de comparação e reintegrado num contexto outro, posto em falso diálogo com um mundo que em nada era seu e que ele ignorara completamente (Ducrot, Benveniste, Kristeva, e mesmo Foucault e Lacan) (SÉRIOT, 2015, p. 12).
\end{abstract}

Nesse sentido, a divulgação na França feita por Julia Kristeva, naquele ano de fervor revolucionário que precedeu o Maio de $68^{8}$, introduz Bakhtin como um teórico que trazia para as discussões intelectuais, então em voga, uma produtividade contestatória. Sériot (2015, p.13) continua sua exposição afirmando que

${ }^{5}$ Genette (2010) define a relação entre o texto principal de uma obra literária e os outros textos que a compõem como paratextualidade. O grupo constituído por “[...] título, subtítulo, intertítulos, prefácios, posfácios, advertências, prólogos, etc.; notas marginais, de rodapé, de fim de texto; epígrafes; ilustrações; release, orelha, capa, e tantos outros tipos de sinais acessórios, autógrafos ou alógrafos" constitui os paratextos de um texto, cuja característica específica é que "fornecem ao texto um aparato (variável) e por vezes um comentário, oficial ou oficioso". Nos paratextos, conforme Genette (2010, p. 16), encontramos “a dimensão pragmática de uma obra, isto é, da sua ação sobre o leitor". Neste sentido, é importante o comentário de alguns paratextos, na medida em que eles aparelham a leitura dos textos da obra de Bakhtin e do Círculo.

${ }^{6} \mathrm{O}$ livro que manuseamos foi traduzido para o Brasil e publicado em função da riqueza de informações que contém. Na França, em sua versão original, o texto foi publicado como prefácio à tradução da obra Marxismo e filosofia da linguagem, preparada por Sériot e Inna Tylkowiski-Ageeva, de 2010. No Brasil, o texto foi acompanhado de um prefácio à edição brasileira, bastante elucidativo de algumas das questões que exploraremos nas próximas páginas sobre a exegese que se faz da obra bakhtiniana.

${ }^{7}$ Alguns textos escritos na juventude de Bakhtin só vieram à luz no final de sua vida, ou mesmo depois de seu falecimento.

${ }^{8}$ Maio de 1968, na França, foi marcado por uma grandiosa onda de protestos que iniciou com manifestações de estudantes que reivindicavam reformas educacionais. Posteriormente, os operários uniram-se aos estudantes, o que levou à maior greve geral da Europa, com cerca de 9 milhões de pessoas, o que balançou o governo francês de Charles de Gaulle. 
Esse catálogo de mal-entendidos ${ }^{9}$ poderia, por si só, servir de introdução a uma história dos devaneios dos intelectuais francófonos daqueles anos em que Marx, Freud e Saussure viviam em harmonia nas páginas da revista Tel Quel e em que a cultura russa chegava em fragmentos, truncada e fantasmada através do filtro das questões políticas e ideológicas do momento (SÉRIOT, 2015, p.13).

A conclusão a que chega Sériot (2015) é que Bakhtin precisaria ser (re)contextualizado, em virtude das especificidades de sua reflexão, que respondem ao entorno de sua época. Em outras palavras, com o exemplo da recepção francesa, o autor destaca a distorção levada a cabo pelo filtro dos francófonos, que descontextualiza a obra. Sériot (2015) se detém especificamente sobre uma questão que nos parece sobremaneira importante para entender como Bakhtin, Volóchinov e Medviédev, o então chamado Círculo, tem sido lido no Brasil.

A análise do discurso discute que os sentidos das palavras são instáveis, que mudam, conforme as formações discursivas em que aparecem. Nessa perspectiva, Sériot (2015) pontua com curiosidade o fato de não nos questionarmos tanto sobre o próprio sentido da palavra "discurso". O autor percebe, pela frequência com que visita e estuda com intelectuais brasileiros e russos, por exemplo, uma nuança bastante específica na leitura que se faz no Brasil e na Rússia da obra: "o termo, a noção, o conceito, a ideia mesma de discurso não tem nenhuma existência na Rússia” (SÉRIOT, 2015, p. 14), constata ainda que "seria dificílimo encontrar tal palavra na imensa exegese bakhtiniana que se desenvolve na Rússia desde o início dos anos 1960" (SÉRIOT, 2015, p. 14). Desse comentário conclui que "Em Bakhtin e Volóchinov, o objeto posto em cena com tanta insistência não é o discurso no sentido de Pêcheux" (SÉRIOT, 2015, p. 14). Se o autor entende que comparando a exegese bakhtiniana no Brasil e na Rússia lá não há sequer a noção de discurso, nós a utilizamos com frequência.

Sériot (2015) traça uma linha comparativa entre a análise de discurso na França e no Brasil e circunscreve a especificidade de ambas no questionamento da centralidade do sujeito, isto é, considerando que a análise do discurso somente faz sentido na medida em que o "sujeito é dividido, de que ele não controla a totalidade de seus dizeres, enquanto vive na ilusão de que é o único autor deles" (SÉRIOT, 2015, p. 14). O autor entende que a problemática bakhtiniana a esse respeito não é antissubjetivista, como em Pêcheux, mas personalista, dessa maneira: "Bakhtin e Volóchinov convocam em seus escritos locutores (indivíduos falantes) e não enunciadores constituídos como sujeitos pelo processo de enunciação" (SÉRIOT, 2015, p. 14). Desse modo, existe em Bakhtin apenas a posição de locutor, afirma Sériot (2015), portanto somente haveria "enunciado, não enunciação, que admitiria por sua vez um sujeito clivado" (SÉRIOT, 2015, p. 14).

Como dissemos anteriormente, Sériot (2015) têm posicionamentos polêmicos e, como tradutor e leitor da obra, faz um recorte específico. O autor tenta, como veremos, afastar com insistência a leitura de Marxismo e filosofia da linguagem ancorada nos parâmetros intelectuais das teorias francesas, quer das teorias enunciativas, quer das

\footnotetext{
${ }^{9}$ Sériot (2015, p.13) faz uma lista de adjetivações absurdas feitas por Kristeva a Bakhtin em texto de 1969, dentre as quais se lê que Bakhtin seria, por exemplo, "continuador dos formalistas", ou estaria na mesma esteira de pensamento de "Saussure dos anagramas", do "Benveniste do discurso", do "Freud da divisão do sujeito", ou do "Marx da Ideologia Alemãa".
} 
teorias discursivas. Nessa perspectiva, percebemos que sua decisão de tradutor é um esforço por recontextualizar ${ }^{10}$ a obra e, simultaneamente, afastar qualquer resquício de possibilidade de leitura comparativa com outros autores franceses. É dessa maneira que, sem haver distinção clara na obra original, o tradutor francês opta por "enunciado" e não "enunciação" para não haver equívocos de interpretação, não aproximando Bakhtin de Benveniste, por exemplo.

No Brasil, a primeira edição em língua portuguesa disponível no mercado foi realizada com tradução indireta do francês e com consultas à tradução do inglês e publicada pela editora Hucitec. Stafuzza (2019, p. 68) observa, nessa tradução, um problema em relação à aproximação entre a teoria da enunciação francesa e o livro Marxismo e filosofia da linguagem: "a hipótese que se arrola é de que a voz teórica da linguística da enunciação foi um dos elementos que constituiu a voz da tradução da edição brasileira que se baseou na versão francesa de MFL [...]”. Ainda de acordo com a autora, essas questões de tradução mostram como a voz do pesquisador também se constitui da voz do tradutor (STAFUZZA, 2019, p. 68). Em outras palavras, a tradução é uma das condições de leitura de uma obra estrangeira. Já na tradução direta recentemente publicada no Brasil pela Editora 34, feita por Sheilla Grillo e Ekaterina Vólkova Américo, ao contrário dessa tradução do francês, também não há a palavra "enunciação", mas sim, "enunciado".

No glossário que acompanha essa tradução de Marxismo e filosofia da linguagem, as tradutoras explicam que a entrada "Enunciado (viskázivanie)" se trata de:

\begin{abstract}
um elo na cadeia da comunicação discursiva e um elemento indissociável das diversas esferas ideológicas [...] O enunciado sempre responde a algo e orienta-se para uma resposta. A análise do enunciado não pode ser feita dentro dos limites da linguística do sistema: aquela tendência de pensamento linguístico que, por meio da abstração, isola a forma linguística do enunciado ("objetivismo abstrato"). "Discurso verbal" ("rietchevóie vistupliénie") e "ato discursivo" ("retchievói akt") são empregados como sinônimos de enunciado (GRILLO; AMÉRICO, 2017, p. 357-358).
\end{abstract}

No mesmo glossário, na entrada "ato discursivo" as tradutoras afirmam que essa noção é comparada a "enunciado" ou, às vezes, concebida como "produto do enunciado". A tradução de Bezerra de Teoria do romance I: A estilística, de Bakhtin (2015b), traz também um glossário de termos ao final, em que se lê na entrada Enunciado:

\title{
[...] no original viskázivanie. Quando se trata do ato de fala ou da produção do discurso, pode- se traduzir o termo como enunciação; mas isto fica por conta da interpretação do tradutor, pois Bakhtin nunca faz nenhuma distinção entre o produto do discurso e o ato de sua produção. [...] (BEZERRA, 2015b, p. 246, negrito nosso).
}

Por fim, Geraldi (2013, p. 16), ao prefaciar sua tradução dos ensaios de Volochínov, em A construção da enunciação e outros ensaios, critica o mesmo texto de Sériot que apresentamos aqui: para o autor brasileiro, a questão se resume em uma pergunta: "De

\footnotetext{
${ }^{10}$ Esse esforço de recontextualizar uma obra no passado será sempre incompleto porque, por mais que regressemos ao passado, teremos sempre uma visão parcial do todo.
} 
que outra forma se deve entender a tradução literal 'o acontecimento do enunciado' senão como “enunciação'?" Geraldi (2013) questiona também o empreendimento de recolocar em contexto o livro:

Seria possível uma leitura contextualizada num tempo que nos é anterior? Seria possível desvestir-se do que se sabe para ler como um homem que nada leu do que se produziu depois da data do texto sobre o que se debruça? [...] Aliás, uma tal leitura, se possível, seria cientificamente útil? (GERALDI, 2013, p. 17).

Ainda sobre a injunção simbólica produzida pelas traduções nos leitores, o termo russo slovo é um caso à parte nas traduções bakhtinianas. Sériot (2015) afirma que, por não encontrar vocábulo equivalente em francês, preferiu usar maiúscula em "Mot" ("Palavra"); o objetivo seria de "chamar atenção do leitor para um campo semântico não apenas amplo, mas ainda em perpétua flutuação" (SÉRIOT, 2015, p. 28). Nessa esteira, a tradução brasileira do termo também sofre deslizamentos de sentido; consultando novamente os mesmos dois glossários que mencionamos acima, Grillo e Américo (2017) e Bezerra (2015b) traduzem, respectivamente, como "palavra" e como "discurso":

[...] tem um significado amplo, que compreende desde a unidade lexical até a "linguagem verbal em uso" ou o enunciado e o discurso. A palavra como sinônimo de enunciado é desenvolvida no último parágrafo do livro [MFL], onde o autor utiliza o composto "palavraenunciado" ("slovo-viskázivanie"). A palavra é uma ponte entre o falante e o interlocutor, pertencente a ambos. No livro [MFL], o conceito de palavra engloba a linguagem verbal, presente em todas as esferas de criação ideológica e da ideologia do cotidiano. A palavra acompanha todo ato de compreensão e interpretação. Na tradução brasileira de Problemas da poética de Dostoiévski (Rio de Janeiro, Forense Universitária, 2008) Paulo Bezerra traduziu o título do último capítulo, "Slovo u Dostoiévskogo", como "O discurso em Dostoiévski", compreendendo que se trata não apenas da unidade lexical, mas também da expressão verbal em geral (negrito nosso) (GRILLO; AMÉRICO, 2017, p. 364-365).

\begin{abstract}
Discurso: no original slovo, que também significa palavra. Minha preferência por discurso leva em conta a maior abrangência e maior propriedade do termo em se tratando de Teoria da Literatura. Troquei ideias a respeito com Serguei Botcharov, um dos mais importantes bakhtinólogos russos e organizador da edição definitiva da obra completa de Bakhtin, que concordou com o emprego de "discurso" em vez de "palavra". [...] (BEZERRA, 2015b, p. 244).
\end{abstract}

Cotejando ambos os fragmentos, destaquemos inicialmente que Grillo e Américo (2017), por traduzirem o mesmo termo ("slovo") diferentemente de uma tradução anterior e já consolidada, iniciam a entrada com a menção ao fato de ter sentido amplo, de recobrir, portanto, o sentido de "discurso". As autoras, contudo, valem-se de uma especificidade da obra em tradução e mencionam a velha fórmula utilizada por Volóchinov, de que a palavra é uma ponte entre interlocutores. Ao mencionar um dos subtítulos de Problemas da poética de Dostoiévski, destacam que o outro tradutor entendeu que "discurso" recobriria com maior espessura semântica o objeto em questão, que seria, naturalmente, maior que "palavra" como item lexical. Em relação ao fragmento do glossário de Bezerra (2015b), o autor pontua a possibilidade de dupla tradução, mas justifica sua escolha em função da especificidade da disciplina em que se insere: a teoria literária. Menciona, ademais, a importância de Serguei Botcharov, um dos estudantes que, nos anos 1960, insistiram para que Bakhtin reeditasse o livro sobre Dostoiévski. 
Nesta seção apresentaremos uma leitura brasileira da obra bakhtiniana desenvolvida por Beth Brait em seus estudos: a análise dialógica do discurso. Para melhor compreender essa questão, revisaremos como emerge ou se consolida essa disciplina brasileira de estudos discursivos com base em dois textos programáticos sobre a chamada Análise Dialógica do Discurso (ADD) introduzidos por um pequeno comentário pautado nos prefácios de quatro importantes coletâneas organizadas por Beth Brait ${ }^{11}$. Os textos programáticos que mencionamos são Análise e teoria do discurso (BRAIT, 2006) e Problemas da poética de Dostoiévski e estudos da linguagem (BRAIT, 2013b).

Primeiramente, localizemos a reflexão de Beth Brait em relação aos textos que analisamos e seu papel como articuladora, de alguma maneira, desse encaminhamento para a exegese da teoria bakhtiniana no Brasil. Como Brait (2005) afirma na introdução a Bakhtin: conceitos-chave, havia a necessidade, naquela época, de uma espécie de glossário dos termos bakhtinianos; os estudantes cobravam um dicionário, que era o projeto inicial, mas depois de uma série de encontros e discussão com os autores que compuseram o elenco daquele livro, esse projeto foi se esfumando e tomou os contornos do livro que conhecemos: uma série de ensaios que se debruçam sobre alguma noção teórica fundamental da obra bakhtiniana.

Um ano mais tarde alguns conceitos haviam ficado de fora, mas foram explorados em Bakhtin: outros conceitos-chave, que segue a mesma tônica de introdução à obra. Em 2009 a autora organizou dois livros; o primeiro traz o título Bakhtin e o Círculo, que continua o projeto dos dois anteriores e tem como "objetivo maior [...] apresentar o que hoje se denomina pensamento bakhtiniano" (BRAIT, 2009, p. 9). Esse livro, contudo, não se detém em conceitos-chave, mas "procura surpreender as especificidades pelo ângulo da rede de textos de dupla assinatura" (BRAIT, 2009, p. 9, grifo da autora); o segundo livro de 2009, que consultamos em sua primeira edição e segunda reimpressão de 2013, intitulado Bakhtin: dialogismo e polifonia, presta-se a tentar

[...] entender os contextos que abrigam Bakhtin no passado e na atualidade, a reflexão sobre o conteúdo específico de cada texto está acompanhada, tanto quanto possível, dos contextos geradores, divulgadores e receptores da obra em pauta (BRAIT, 2013a, p. 11).

Tomando esses quatro livros e esse brevíssimo comentário que contextualiza as introduções assinadas pela organizadora, podemos perceber um esforço por tornar a obra mais acessível a uma maioria de leitores em formação e com um crescente interesse em ler Bakhtin. Esse seria o contexto em que emerge essa teoria de base bakhtiniana à moda brasileira.

\footnotetext{
11 As coletâneas são: Bakhtin: conceitos-chave (2005), Bakhtin: outros conceitos-chave (2006), Bakhtin: dialogismo e polifonia (2009) e Bakhtin e o Círculo (2009). Todas essas obras foram consultadas em suas primeiras edições exceto Bakhtin: dialogismo e polifonia, que consultamos a primeira edição, porém segunda reimpressão, por isso, a data que consta nas referências é do ano de 2013.
} 
Em Análise e teoria do discurso (BRAIT, 2006) temos acesso a um trabalho em processo de consolidação para analisar discursos com base na teoria dialógica. Brait (2006) afirma que:

\begin{abstract}
Ninguém, em sã consciência, poderia dizer que Bakhtin tenha proposto formalmente uma teoria e/ou análise do discurso, no sentido em que usamos a expressão para fazer referência, por exemplo, à Análise do Discurso Francesa. Entretanto, também não se pode negar que o pensamento bakhtiniano representa, hoje, uma das maiores contribuições para os estudos da linguagem, observada tanto em suas manifestações artísticas como na diversidade de sua riqueza cotidiana. Por essa razão, mesmo consciente de que Bakhtin, Voloshinov ${ }^{12}$, Medvedev ${ }^{13} \mathrm{e}$ outros participantes do que atualmente se denomina Círculo de Bakhtin jamais tenham postulado um conjunto de preceitos sistematicamente organizados para funcionar como perspectiva teórico-analítica fechada, esse ensaio arrisca-se a sustentar que o conjunto das obras do Círculo motivou o nascimento de uma análise/teoria dialógica do discurso, perspectiva cujas influências e consequências são visíveis nos estudos linguísticos e literários e, também, nas Ciências Humanas de maneira geral (BRAIT, 2006, p. 9-10, negrito nosso).
\end{abstract}

Sobre esse fragmento, podemos tecer alguns comentários: primeiramente, o fato de não haver sido proposta formalmente por Bakhtin uma teoria e/ou análise do discurso, já evidenciando, também, a distância segura que se deve ter dessa expressão com larga tradição francesa. Veremos que as expressões "teoria e/ou análise do discurso" e "análise/teoria dialógica do discurso" aparecerão no todo desse ensaio de maneira frequente se referindo à leitura/exegese do pensamento bakhtiniano no Brasil sistematizado por Beth Brait e seu grupo. Percebemos também que, ao tratar do próprio ensaio, a autora afirma que "arrisca-se a sustentar" uma contribuição para a análise dos discursos que tenha como característica o uso de categorias dialógicas.

Mais adiante, Brait (2006) segue sua exposição sempre com certo cuidado em relação à instabilidade que pode ser produzida pela leitura, já que até aquele momento a Análise Dialógica do Discurso não estava consolidada e era imprescindível um afastamento da Análise de Discurso Francesa, derivada de Pêcheux, já consolidada no Brasil. Nesse sentido, a autora ressalta a necessidade de conceber os estudos da linguagem como

[...] formulações em que o conhecimento é concebido, produzido e recebido em contextos históricos e culturais específicos e, ao mesmo tempo, reconhecer que essas atividades intelectuais e/ou acadêmicas são atravessadas por idiossincrasias institucionais e, necessariamente, por uma ética que tem na linguagem, e em suas implicações nas atividades humanas, seu objetivo primeiro (BRAIT, 2006, p. 10).

"Para perseguir essa hipótese (ou tese)", de que seria possível desenvolver uma teoria/análise do discurso dialógica em função da contribuição bakhtiniana para os estudos da linguagem e para a teoria da literatura, a autora parte da metalinguística de Bakhtin (2015a) - retomamos este ponto a seguir. Considerando essa flutuação das expressões "teoria e/ou análise do discurso" e "análise/teoria dialógica do discurso" e o

\footnotetext{
${ }^{12}$ Grafado como no original.

${ }^{13}$ Idem nota anterior.
} 
caráter de trabalho em andamento flagrado pelo verbo "arrisca-se" em relação à proposta, tanto quanto essa relação entre "hipótese/tese" dão a tônica dessa introdução de uma teoria que emerge para contribuir em um dos canteiros de trabalho mais férteis nos estudos da linguagem no Brasil.

Nessa proposta, Brait (2006) começa a apresentar alguns dos conceitos que têm importância para sua leitura da teoria de Bakhtin e, nesse contexto, começa a explorar, justamente, uma das obras que foi sempre mais lida pelos estudiosos da literatura, Problemas da poética de Dostoiévski. É nesse livro que aparece a expressão "metalinguística", que o autor russo considera ser uma aposta metodológica importante de sua teoria:

Podem ser situadas na Metalinguística, subentendendo-a como um estudo - ainda nãoconstituído em disciplinas particulares definidas - daqueles aspectos da vida do discurso que ultrapassam - de modo absolutamente legítimo - os limites da Linguística (BAKHTIN, 2015a, p. 207).

Brait (2006) explica que Bakhtin refina seu objeto e, nas próximas páginas desse livro, substitui a expressão "discurso" por "relações dialógicas", localizando-a em uma perspectiva que leva em consideração tanto o linguístico quanto o extralinguístico. A autora afirma que

\begin{abstract}
O trabalho metodológico, analítico e interpretativo com textos/discursos se dá [...] herdando da Linguística a possibilidade de esmiuçar campos semânticos, descrever e analisar micro e macro organizações sintáticas, reconhecer, recuperar e interpretar marcas e articulações enunciativas que caracterizam o(s) discurso(s) e indiciam sua heterogeneidade constitutiva, assim como a dos sujeitos aí instalados. E mais ainda: ultrapassando a necessária análise dessa "materialidade linguística", reconhecer o gênero a que pertencem os textos e os gêneros que nele se articulam, descobrir a tradição das atividades em que esses discursos se inserem e, a partir desse diálogo com o objeto de análise, chegar ao inusitado de sua forma de ser discursivamente, à sua maneira de participar ativamente de esferas de produção, circulação e recepção, encontrando sua identidade nas relações dialógicas estabelecidas com outros discursos, com outros sujeitos (BRAIT, 2006, p. 13-14).
\end{abstract}

Nesse ínterim, o trabalho metodológico que serviria de base à análise se apropria dos desenvolvimentos da linguística, estudando o funcionamento da materialidade, mas passando para o exterior, em relação à maneira como os discursos são produzidos, circulam ou são recebidos em sociedade. Brait (2006) destaca que a teoria/análise do discurso dialógica não trabalha com um arsenal teórico fechado, sistematicamente preparado, e que poderia ser mecanicamente aplicada ao estudo discursivo.

O próprio livro Problemas da poética de Dostoiévski é exemplo desse raciocínio, uma vez que Bakhtin (2015a) faz primeiramente uma exposição do todo da obra de Dostoiévski, seguida da configuração do gênero polifônico para, por último, apresentar o conceito de polifonia. Em outras palavras, os dados exigem o conceito, não o contrário. A autora conclui que uma das características específicas dessa teoria/análise dialógica do discurso é: "não aplicar conceitos a fim de compreender um discurso, mas deixar que os discursos revelem sua forma de produzir sentido, a partir de ponto de vista dialógico, num 
embate" (BRAIT, 2006, p. 23). Dito de outro modo, a orientação é tentar pensar com Bakhtin usando técnicas de seleção e de leitura dos dados como aquelas exemplificadas sobremaneira em seus dois livros que contêm maior esforço analítico: Problemas da poética de Dostoiévski e A cultura popular na Idade Média e no Renascimento: o contexto de François Rabelais.

Percebemos uma flutuação da nomenclatura nesse ensaio, uma vez que Brait (2006b) usa "Análise e teoria do discurso", no título, e em meio ao texto as variantes "teoria e/ou análise do discurso", "análise/teoria dialógica do discurso", "teoria/análise dialógica do discurso", "teoria/análise dialógica". No título podemos afirmar que a coordenação iniciada por "Análise" e depois por "Teoria" tem como objetivo afastar a palavra "análise" da palavra "discurso", o que faz bastante sentido levando-se em conta o primeiro parágrafo do ensaio que citamos anteriormente, no qual faz-se questão de afastar a ADD em construção da Análise do discurso francesa já consolidada.

Por outro lado, Brait (2013b) ${ }^{14}$, em Problemas da poética de Dostoiévski e estudos da linguagem, diminui essa flutuação terminológica e utiliza apenas um dos termos, que viria a se consolidar, mais tarde:

\begin{abstract}
Ao contrário do que se possa imaginar, ou seja, que esse conjunto de resenhas constitua um panorama meramente histórico (motivando alguns leitores a pular essa parte...), os textos vão sendo costurados com elementos que sinalizam a perspectiva bakhtiniana da linguagem e não somente seu interesse por Literatura e Poética ${ }^{15}$. Isso fica patente em vários momentos desse primeiro capítulo, mas especialmente no trecho em que Bakhtin se refere às relações dialógicas, fenômeno que, em outro capítulo, será tratado como o objeto da Translinguística, ou do que hoje se poderia chamar de Análise Dialógica do Discurso (BRAIT, 2013b, p. 55).
\end{abstract}

Nesse sentido, realizando um batimento entre Brait (2006) e Brait (2013b), percebemos que aquilo que havia de flutuação no primeiro texto se esfuma à medida que as discussões em torno da obra bakhtiniana permitem diferenciar a "Análise dialógica do discurso" de outras análises de discurso. Sem se desfazer das especificidades da posição teórico-metodológica adotada no bojo da reflexão do Círculo de Bakhtin, a ADD se configuraria à diferença de outras análises discursivas, com uma característica central e indispensável: seu caráter dialógico.

\title{
5 CONSIDERAÇÕES FINAIS
}

Desse conjunto formado pelas discussões que fizemos podemos tecer algumas questões que ainda ficarão em aberto, como o desenvolvimento nos próximos anos da(s) leitura(s) bakhtinianas no Brasil. Parece fato que a expressão "Análise dialógica do discurso", ou simplesmente ADD, já está consolidada academicamente, sobretudo em função da possibilidade de estudar discursos que se materializam em superfícies textuais verbais, visuais, ou vocais, ou ainda, verbovocovisuais.

\footnotetext{
${ }^{14}$ É importante destacar que a obra aqui consultada é a primeira edição em sua segunda reimpressão, do ano de 2013. A primeira impressão é de 2009.

15 Trata-se da obra de Bakhtin (2015).
} 
Vimos, neste percurso, que recuperamos condições de leitura muito específicas que deram ensejo para a emergência de uma ADD no Brasil. Uma dessas questões é a influência que sofremos dos franceses - não somente no Brasil, mas no Ocidente de modo mais geral - na recepção inicial de Bakhtin e do Círculo. Uma segunda questão é que recebemos essas obras fragmentariamente durante três décadas, a maior parte delas em traduções cotejadas com outras línguas, o que passava pelo crivo de dois ou mais tradutores de línguas diferentes. A dificuldade de acesso aos arquivos em russo é outro parâmetro que condiciona nossa leitura, quase sempre - porque agora temos um grupo de tradutores competentes lendo e retraduzindo diretamente dos arquivos.

Nesse sentido, a(s) leitura(s) de Bakhtin no Brasil são condicionadas diretamente pela chegada fragmentária dos textos, pelas traduções - diretas ou indiretas - pela exegese no exterior. Consideramos que a(s) exegese(s) brasileira(s) da obra bakhtiniana se $\operatorname{adapta}(m)$ às condições de leitura que nos são acessíveis, na medida em que a maioria dos leitores de Bakhtin e do Círculo no Brasil lê os textos em tradução e que a recepção internacional - da chamada redescoberta nos anos 1960 na Rússia ao momento atual de interação com os escritos - interfere na produção de sentidos e na divulgação das ideias. A questão central na proposição da Análise Dialógica do Discurso é a coerência com os pressupostos teórico-metodológicos do Círculo de Bakhtin e o estudo de discursos à moda brasileira. A leitura singular feita por Beth Brait no Brasil tenta expandir as contribuições bakhtinianas para a análise de materialidades diversas, de objetos muito além daqueles imaginados pelos autores russos; tenta transladar os autores "Da Rússia Czarista à web" (BRAIT; CAMPOS, 2009) como uma metáfora da amplitude do alcance dessa teoria discursiva no Brasil.

\section{REFERÊNCIAS}

BAKHTIN, M. M. Problemas da poética de Dostoiévski. Tradução de Paulo Bezerra. 5. ed. São Paulo: Forense Universitária, 2015a. 341p.

BAKHTIN, M. M. Teoria do romance I: a estilística. Tradução, prefácio e glossário de P. Bezerra. São Paulo: Editora 34, 2015b. 256 p.

BAKHTIN, M. M. Questões de estilística no ensino da língua. Tradução, posfácio e notas de Sheila Grillo e Ekaterina Vólkova Américo. São Paulo: Editora 34, 2013. 120p.

BARONAS, R. L. (Org.). Estudos discursivos à brasileira: uma introdução. Campinas: Pontes Editores, 2015. 191p.

BEZERRA, P. Prefácio - uma obra à prova do tempo. In: BAKHTIN, M.M. Problemas da poética de Dostoiévski. Tradução de Paulo Bezerra. 5. ed. São Paulo: Forense Universitária, 2015a. p. V-XXII.

BEZERRA, P. Breve glossário de alguns conceitos-chave. In: BAKHTIN, M.M. Teoria do romance I: a estilística. Tradução, prefácio e glossário de P. Bezerra. São Paulo: Editora 34, 2015b. p. 243-249.

BRAIT, B. Análise e teoria do discurso. In: BRAIT, B. (Org.). Bakhtin: outros conceitos-chave. São Paulo: Contexto, 2006. p. 9-31.

BRAIT, B. CAMPOS, M. I. B. Da Rússia czarista à Web. In: BRAIT, B. (Org.). Bakhtin e o círculo. São Paulo: Contexto, 2009. p. 15-30.

BRAIT, B. Introdução - Alguns pilares da arquitetura bakhtiniana. In: BRAIT, B. (Org.). Bakhtin: conceitos-chave. São Paulo: Contexto, 2005. p. 7-10.

BRAIT, B. Introdução. In: BRAIT, B. (Org.). Bakhtin e o círculo. São Paulo: Contexto, 2009. p. 9-11.

BRAIT, B. Introdução. In: BRAIT, B. (Org.). Bakhtin: polifonia e dialogismo. 1. ed. 2. reimpr. São Paulo: Contexto, 2013a. p. 11-13. 
BRAIT, B. Problemas da poética de Dostoiévski e estudos da linguagem. In: BRAIT, B. (Org.). Bakhtin: polifonia e dialogismo. 1. ed. 2. reimpr. São Paulo: Contexto, 2013b. p. 45-72.

BUBNOVA, T. Do corpo à palavra: leituras bakhtinianas. Organização, tradução e notas de Nathan Bastos de Souza. São Carlos: Pedro \& João Editores, 2016. 253 p.

GENETTE, G. Palimpsestos. A literatura de segunda mão. Tradução de Cibele Braga et. al. Belo Horizonte: Edições Viva Voz, 2010. 172 p.

GERALDI, J. W. Introdução. O mundo não nos é dado, mas construído. In: VOLOCHÍNOV, V. N. A construção da enunciação e outros ensaios. Organização, tradução e notas de João Wanderley Geraldi. São Carlos: Pedro \& João Editores, 2013. p.7-27.

GRILLO, S. C. Prefácio - A obra em contexto: tradução, história e autoria. In: MEDVIÉDEV, P. N. $O$ método formal nos estudos literários. Introdução crítica a uma poética sociológica. Trad. E. V. Américo e S. C. Grillo. São Paulo: Contexto, 2012. p.19-39.

GRILLO, S. Ensaio introdutório. In: VOLÓCHINOV, V.N. Marxismo e filosofia da linguagem: problemas fundamentais do método sociológico na ciência da linguagem. Tradução, notas e glossário de S. Grillo e E. V. Américo. São Paulo: Editora 34, 2017. p. 7-79.

GRILLO, S. O retrato de Mikhail Bakhtin em sua mais recente biografia russa (2017). In: BRAIT, B.; PISTORI, M. H.C.; FRANCELINO, P. F. (Org.). Linguagem e conhecimento (Bakhtin, Volóchinov, Medviédev). Campinas: Pontes, 2019. p. 15-42.

GRILLO, S.; AMÉRICO, E. V. Glossário. In: VOLÓCHINOV, V. N. Marxismo e filosofia da linguagem: problemas fundamentais do método sociológico na ciência da linguagem. Tradução, notas e glossário de S. Grillo e E. V. Américo. São Paulo: Editora 34, 2017. p. 353-368.

KRISTEVA, J. Dialogisme, carnavalesque et psychanalyse: entretien avec Julia Kristeva sur la réception de l'oeuvre de Mikhail Bakhtine en France. Entrevista concedida a Clive Thonson. Recherches sémiotique/Semiotic Inquiry, v. 18, n. 1-2, p. 15-30, 1998.

MEDVIÉDEV, P. N. O método formal nos estudos literários. Introdução crítica a uma poética sociológica. Tradução de E. V. Américo e S. C. Grillo. São Paulo: Contexto, 2012. 269 p.

PAULA, L.; STAFUZZA, G. B. Apresentação. In: PAULA, L.; STAFUZZA, G. B. (Org.). Da análise do discurso no Brasil à análise do discurso do Brasil: três épocas histórico-analíticas. Uberlândia: EDUFU, 2010. p. 11-17.

PONZIO, A. Cronologia. In: PONZIO, A. A revolução bakhtiniana. Coordenação de tradução de V. Miotello. 2. ed. São Paulo: Contexto, 2012. p. 322-332.

POSSENTI, S.; BARONAS, R. L. (Org.). Contribuições de Dominique Maingueneau para a análise do discurso do Brasil. São Carlos: Pedro \& João Editores, 2008. 212 p.

SÉRIOT, P. Vološinov e a filosofia da linguagem. Tradução de M. Bagno. São Paulo: Parábola Editorial, 2015. $128 \mathrm{p}$.

STAFUZZA, G. B. O Círculo de Bakhtin (Volóchinov e Medviédev) no Brasil: episteme, autoria e tradução em perspectiva dialógica. Heterotópica, Uberlândia, v. 1, n. 1, p. 66-82, jan./jun. 2019.

VOLÓCHINOV, V. N. Marxismo e filosofia da linguagem: problemas fundamentais do método sociológico na ciência da linguagem. Tradução, notas e glossário de S. Grillo e E. V. Américo. São Paulo: Editora 34, 2017. 376 p.

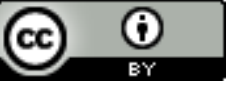

Este texto está licenciado com uma Licença Creative Commons Atribuição 4.0 Internacional. 